\title{
Recombinase Polymerase Amplification Assay for Field Detection of Tomato Bacterial Spot Pathogens
}

\author{
A. Strayer-Scherer, ${ }^{1}$ J. B. Jones, ${ }^{1, \dagger}$ and M. L. Paret $2, \dagger$ \\ ${ }^{1}$ Department of Plant Pathology, University of Florida, Gainesville 32611; and 2Department of Plant Pathology, North Florida Research and \\ Education Center, University of Florida, Quincy 32351 \\ Accepted for publication 11 September 2018.
}

\begin{abstract}
Bacterial spot of tomato is caused by Xanthomonas gardneri, $X$. euvesicatoria, $X$. perforans, and $X$. vesicatoria. Current diagnostic methods for the pathogens are not in-field assays. Recombinase polymerase amplification (RPA) is ideal for in-field detection assays, because it is an isothermal technique that is rapid and more tolerant to inhibitors compared with polymerase chain reaction. Hence, novel RPA probes and primers were designed to amplify regions of the $h r c N$ gene of $X$. gardneri, $X$. euvesicatoria, and $X$. perforans. The $X$. gardneri RPA is specific to $X$. gardneri with a detection limit of $10^{6} \mathrm{CFU} / \mathrm{ml}$ and detected $X$. gardneri in lesions from naturally $(n=6)$ or artificially $(n=18)$ infected plants. The $X$. euvesicatoria RPA detects both $X$. euvesicatoria and $X$. perforans with a detection limit of $10^{6} \mathrm{CFU} / \mathrm{ml}$ and detected both pathogens in
\end{abstract}

ABSTRACT

Bacterial spot is one of the most important diseases of tomato that occurs worldwide, having a high negative impact on tomato production in warm, humid regions (Jones et al. 2004; Pohronezny and Volin 1983; Potnis et al. 2015; Scott et al. 1989). This disease is incited by four distinct species of the genus Xanthomonas, which include $X$. euvesicatoria, X. gardneri, X. perforans, and $X$. vesicatoria (Jones et al. 2004). Historically, X. euvesicatoria and $X$. vesicatoria were more widely distributed, with the other two species being less prevalent (Potnis et al. 2015). However, in recent years, $X$. perforans and $X$. gardneri have been more frequently isolated worldwide (Potnis et al. 2015). Infection can result in leaf and fruit lesions, defoliation, and yield losses of $\leq 50 \%$ (Louws et al. 2001). Leaf lesions are initially circular and water soaked in appearance but turn dark brown to black with a wet or greasy appearance (Ritchie 2000; Vallad et al. 2004). Although X. perforans leaf lesions can develop a shot-hole appearance, it can be difficult to differentiate the four bacterial spot pathogens by symptoms alone (Stall et al. 2009).

Various techniques, such as carbon utilization, fatty acid profiles, 16S ribosomal RNA sequence analysis, and DNA-DNA hybridization, have been used to identify plant pathogenic xanthomonads in the past (Bouzar et al. 1994; Cho and Tiedje 2001; Jones et al. 2004; Vauterin et al. 1995; Yang et al. 2005). Although DNA-DNA hybridization has been used to define a bacterial species, it is not practical for analyzing large numbers of bacterial strains (Cho and

${ }^{\dagger}$ Corresponding authors: J. B. Jones; E-mail: jbjones@ufl.edu, and M. L. Paret; E-mail: paret@ufl.edu

Funding: Funding for this work comes from the startup funds provided by the Dean for Research, Institute of Food and Agricultural Sciences, University of Florida (to M. L. Paret).

*The $e$-Xtra logo stands for "electronic extra" and indicates that one supplementary figure and one supplementary table are published online.

The author(s) declare no conflict of interest.

C 2019 The American Phytopathological Society plants artificially infected $(n=36)$ or naturally infected $(n=85)$ with either $X$. euvesicatoria or X. perforans. The $X$. perforans RPA is specific to $X$. perforans with a detection limit of $10^{7} \mathrm{CFU} / \mathrm{ml}$. Although the $X$. perforans RPA assay was unable to detect $X$. perforans from lesions, the $X$. euvesicatoria RPA was successfully used in field to detect $X$. perforans from symptomatic field samples $(n=31)$. The $X$. perforans RPA was then used to confirm the pathogen in the laboratory. The $X$. euvesicatoria and X. gardneri RPA is promising for rapid, real-time infield detection of bacterial spot and one of the first developed among plant pathogenic bacteria.

Additional keyword: bacteriology.

Tiedje 2001; Rademaker et al. 2000). In recent years, the ability to identify xanthomonads to species has greatly improved because of advances in DNA-based technology. In terms of the bacterial spot pathogens, conventional polymerase chain reaction (PCR) and realtime PCR (quantitative PCR) diagnostic assays have been developed (Araújo et al. 2012; Leite et al. 1994; Obradovic et al. 2004; Strayer et al. 2016). Leite et al. (1994) designed PCR primers based on $h r p B$ gene (more specifically, the $h r c N$ ) sequences and used restriction enzyme analysis (REA) for differentiating between 28 different pathovars of $X$. campestris, which resulted in unique and distinctive banding patterns for different pathovars of the genus Xanthomonas. The hrpB operon belongs to the hypersensitive response and pathogenicity gene cluster ( $h r p)$ and is essential for type III protein secretion and pathogenicity (Rossier et al. 2000). Most plant pathogenic xanthomonads have a type III secretion system that delivers effector proteins into the host cell to downregulate host defense responses (Alfano and Collmer 2004; Bonas et al. 1991; Cornelis 2006; Noël et al. 2002). To make a detection assay specific to the bacterial spot pathogens, Obradovic et al. (2004) designed PCR primers to amplify a 420-bp fragment of the $h r p B$ from 39 strains representing the four species that cause bacterial spot. The PCR products were digested with three restriction enzymes, which resulted in distinct banding patterns for the four pathogens. Although effective and accurate, this method utilizes gel electrophoresis and restriction enzyme digest, which can be time consuming when analyzing large collections of strains. Strayer et al. (2016) targeted the $h r c N$ gene and designed a multiplex real-time PCR assay to simultaneously detect all four bacterial spot pathogens. Four species-specific probes and two primer sets were designed to amplify smaller regions within the 420-bp region of the $h r p B(h r c N)$ as identified by Obradovic et al. (2004). This detection assay effectively and accurately amplified DNA extracted from 72 pure cultures representing the four bacterial pathogens and from 122 tomato leaflets and two tomato fruits infected with bacterial spot. Because it saves time when processing large sample numbers, it is an improvement over gel-based detection techniques. 
Instead of targeting a region of the $h r c N$, Araújo et al. (2012) developed a multiplex PCR to simultaneously detect all four species by utilizing oligonucleotide primers that were previously designed based on amplified fragment length polymorphism (AFLP) analysis (Koenraadt et al. 2009). Although this method effectively detected and differentiated the four bacterial spot pathogens, it is gel based and labor intensive, especially when processing large samples. Furthermore, it is unclear how conserved the regions of DNA are that are targeted by these primers. Two bacterial spot strains (X. euvesicatoria strain NI1 and X. perforans strain 17-12) were identified that do not contain the genomic sequences that these primers are intended to amplify (N. Potnis, unpublished data). One of the strains NI1, which was isolated from tomato in Nigeria, was determined based on whole-genome sequencing to be more closely related to $X$. perforans, although there was significant recombination with $X$. euvesicatoria (M. Jibrin, unpublished data). Although NI1 behaves like $X$. perforans in terms of host differential reactions on tomato, it is more closely related to $X$. euvesicatoria based on multilocus sequence analysis (MLSA) using six housekeeping genes (Timilsina et al. 2015). Given that the primers designed by Araújo et al. (2012) will not amplify all of the xanthomonads associated with tomato, a more conserved region of DNA should be used to consistently identify the four bacterial spot pathogens.

Currently, all of the diagnostic assays available for the bacterial spot of tomato pathogens require samples to be collected and processed in the laboratory, which can be time consuming. This can be problematic for tomato producers who need a rapid diagnosis to make the proper disease management decisions. They would benefit from the development of an in-field diagnostic assay. Recombinase polymerase amplification (RPA) is an ideal candidate for in-field diagnostic assays, because it is rapid and overcomes the technical difficulties of PCR and real-time PCR (Zanoli and Spoto 2012). RPA is an isothermal nucleic acid amplification method that does not require thermal denaturation of the template and operates at a low constant temperature (from 37 to $42^{\circ} \mathrm{C}$ ) (Piepenburg et al. 2006; Silva et al. 2015). It does so by utilizing three core enzymes: recombinase, single-stranded binding protein (SSB), and stranddisplacing polymerase. The recombinase enzyme forms a complex with oligonucleotide primers to facilitate their binding to the targeted DNA template in contrast to PCR and real-time PCR, which require the global melting of the template (Kim and Easley 2011; Mackay et al. 2002; Piepenburg et al. 2006; Schochetman et al. 1988). Then, the SSB binds to the displaced strands of DNA and prevents the displacement of recombinase-primer complex by branch migration. The strand-displacing polymerase then recognizes the bound recombinase-primer complex and initiates DNA synthesis (Piepenburg et al. 2006). Additional enzymes, such as a reverse transcription, endonuclease IV, or exonuclease III, can be added to provide extra functionalities (Piepenburg et al. 2006; Silva et al. 2015). In this study, we explore the use of an exonuclease III enzyme, which allows for the real-time detection of fluorescent oligonucleotide probes (TwistAmp exo probe) (Piepenburg et al. 2006; Zanoli and Spoto 2012). A TwistAmp exo probe consists of an oligonucleotide that contains an abasic nucleotide analog (tetrahydrofuran $[\mathrm{THF}]$ residue) that replaces a nucleotide in the target sequence, which is flanked by a dT-fluorophore and a dT-quencher group (TwistDx 2017). The exonuclease III will cleave each exo probe at the THF residue to separate the fluorophore from the quencher to generate a fluorescent signal (Piepenburg et al. 2006; TwistDx 2017). Additionally, portable RPA instruments are available for purchase from both TwistDx Ltd. (Cambridge, UK) and Agdia, Inc. (Elkhart, IN) for real-time detection in the field and laboratory settings.

In general, RPA is an ideal candidate for in-field diagnostic assays, because it is rapid, operates at a single reaction temperature, is portable and easy to use, and is more tolerant to inhibitors present in crude samples than conventional PCR and real-time PCR (Zanoli and Spoto 2012). Thus, the goal of this study was to develop and evaluate four simplex (a single RPA reaction with one probe and primer set) RPA assays that utilize exo probes and primers to detect and differentiate the four Xanthomonas spp. that cause bacterial spot of tomato. The specific objectives of this study were to (i) design RPA exo probes and primers to differentially target the four pathogens in the $h r c N$ gene, (ii) develop and optimize individual simplex RPA assays to detect each of the four pathogens, and (iii) test the sensitivity and accuracy of each RPA assay using pure cultures and artificially and naturally infected plant samples.

\section{MATERIALS AND METHODS}

Isolation and storage of bacterial strains. Bacterial strains used in this study are listed in Table 1. Bacteria were grown on nutrient agar (NA; BBL; Becton Dickinson and Co., Cockeysville, MD) at $28^{\circ} \mathrm{C}$ and subcultured every 24 to $48 \mathrm{~h}$. For long-term storage, purified cultures were stored in sterile deionized water containing $30 \%$ glycerol at $-80^{\circ} \mathrm{C}$. The strains in Table 1 were also characterized using race differentiation and real-time PCR (Obradovic et al. 2004; Strayer et al. 2016). The strains listed in Table 1 were previously isolated from naturally infected plant tissue for RPA analysis. Bacteria were isolated from artificially and naturally infected plant tissue collected in this study for RPA analysis. Individual lesions ( $\sim 1$ to $2 \mathrm{~mm}$ in size) were aseptically cut from tomato. The diseased tissue was transferred to $25 \mu \mathrm{l}$ of sterile tap water in a Petri dish and macerated using a sterile scalpel. To obtain pure cultures, a small amount of this suspension was streaked with a sterile inoculating loop for individual colonies on NA.

Bacterial DNA extraction from pure cultures and infected plant tissue. For pure cultures and plant tissue, an extraction buffer containing $20 \mathrm{mM}$ 2-amino-2-hydroxymethyl1,3-propanediol (pH 8.0; Thermo Fisher Scientific, Waltham, MA), $2 \mathrm{mM}$ (ethylenedinitrilo) tetraacetic acid ( $\mathrm{pH}$ 8.0; Thermo Fisher Scientific), and 1\% TritonX100 (Thermo Fisher Scientific) was used to lyse bacterial cells and release bacterial DNA. DNA was extracted by lysis in the extraction buffer alone or in combination with the boiling bacterial cells from pure cultures grown at $28^{\circ} \mathrm{C}$ for $24 \mathrm{~h}$. For the extraction buffer-only method, DNA was extracted from pure cultures as follows. Using the end of a sterile toothpick, a small number of bacterial cells were transferred from pure cultures to a sterile $1.5-\mathrm{ml}$ capped microcentrifuge tube containing $400 \mu \mathrm{l}$ of extraction buffer and vortexed for $30 \mathrm{~s}$. The tubes were incubated at room temperature for $15 \mathrm{~min}$, centrifuged $(16,872 \times g)$ for $1 \mathrm{~min}$, and transferred to ice for RPA analysis. For the boiling method, DNA was extracted from pure cultures as follows. Using the end of a sterile toothpick, a small number of bacterial cells were transferred from a pure culture to a sterile $1.5-\mathrm{ml}$ capped microcentrifuge tube containing $400 \mu \mathrm{l}$ of extraction buffer. These tubes were incubated at $100^{\circ} \mathrm{C}$ for $20 \mathrm{~min}$, transferred to ice for $5 \mathrm{~min}$, and centrifuged $(16,872 \times g)$ for $5 \mathrm{~min}$. The tubes were then transferred to ice until RPA analysis was completed.

DNA was extracted by lysis in the extraction buffer alone or in combination with boiling infected tissue samples. For the extraction buffer-only method, DNA was extracted from infected plant tissue as follows. Three to four individual bacterial spot lesions $(\sim 1$ to $2 \mathrm{~mm}$ in size) were aseptically cut from each artificially or naturally infected tomato leaf, stem, or fruit and combined into one sample. Lesions were transferred to sterile $1.5-\mathrm{ml}$ capped microcentrifuge tubes containing $200 \mu \mathrm{l}$ of extraction buffer and macerated using a sterile pestle. Plant debris was allowed to settle to the bottom of the tube for $15 \mathrm{~min}$ and transferred to ice for RPA analysis. For the boiling method, DNA was extracted from infected plant tissue as follows. Three to four individual bacterial spot lesions per sample ( $\sim 1$ to $2 \mathrm{~mm}$ in size) were aseptically cut from artificially or naturally infected tomato leaves, stems, and fruit. Lesions were then transferred to sterile $1.5-\mathrm{ml}$ capped microcentrifuge tubes containing $200 \mu \mathrm{l}$ of extraction buffer and macerated using a sterile pestle. The samples were then incubated at $100^{\circ} \mathrm{C}$ for $20 \mathrm{~min}$, transferred to 
ice for $5 \mathrm{~min}$, and centrifuged $(16,872 \times g)$ for $5 \mathrm{~min}$. The tubes were then transferred to ice until RPA analysis was completed.

RPA exo probe and primer design. The $h r c N$ gene sequences of the bacterial spot xanthomonads were obtained from the National Center of Biotechnology Information (NCBI) database to target each of the four bacterial spot pathogens: $X$. gardneri (AEQX00000000), X. euvesicatoria 85-10 (AM039952), $X$. perforans 91-118 (AEQW00000000), and X. vesicatoria ATCC 35937 (AEQV00000000). Four RPA exo probes and three RPA primer sets were designed to target the $h r c N$ gene sequences of the

TABLE 1. Bacterial strains used in this study for the validation of the simplex (single reaction with one probe and primer set) recombinase polymerase amplification (RPA) assays and reaction results of each simplex RPA

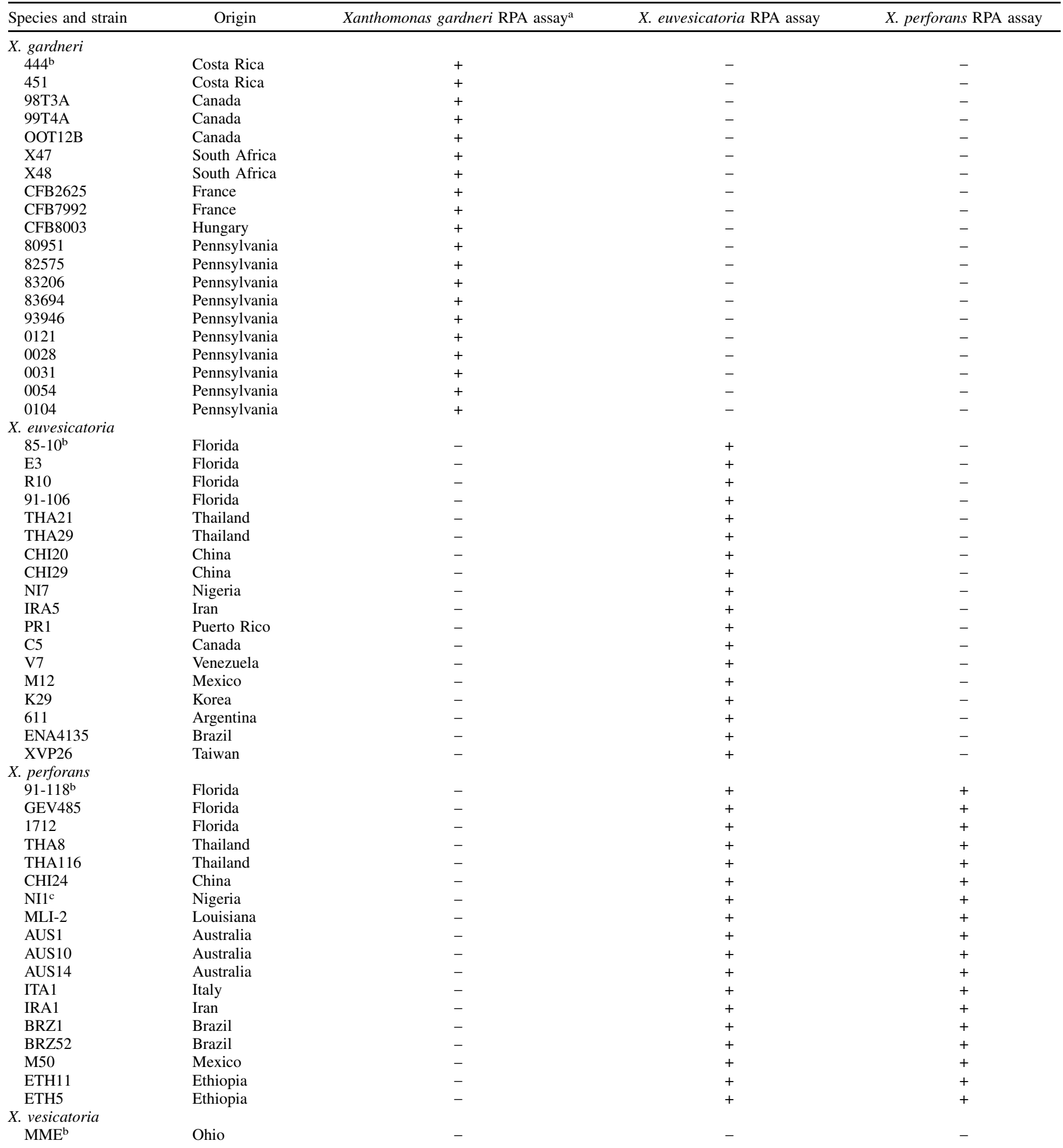

a The + symbol indicates that DNA extracted from the pure culture of the strain was amplified by the RPA exo probe and primer set for X. euvesicatoria, X. gardneri, $X$. perforans, and/or X. vesicatoria, and the - symbol indicates that DNA extracted from the pure culture of the strain was not amplified by the RPA exo probe and primer set for X. euvesicatoria, X. gardneri, X. perforans, and/or X. vesicatoria.

b DNA extracted from bacterial spot strains 444, 85-10, 91-118, and MME was used to optimize and determine sensitivity of each RPA assay.

${ }^{c}$ Based on whole-genome sequencing, X. perforans strain NI1 was determined to be more closely related to X. perforans, although there was significant recombination with $X$. euvesicatoria (M. Jibrin, unpublished data). 
four bacterial spot pathogens (Table 2). Exo probes were designed manually to have the following characteristics when possible: 30 to $70 \%$ guanine-cytosine (GC) content, runs of more than four identical nucleotides were avoided, secondary structures with a melting temperature $\left(\mathrm{T}_{\mathrm{m}}\right)$ between 37 and $42^{\circ} \mathrm{C}$ were avoided, and probes were 46 to 52 nucleotides in length ( 30 and 15 of which were placed $5^{\prime}$ and $3^{\prime}$, respectively, to the THF site). Because the internal labels used in TwistAmp exo probes are only readily available on thymines, two thymines with fewer than six intervening nucleotides were selected in each target sequence to be labeled with FAM and black hole quencher 1 . A single nucleotide within the two modified thymines (dT) was selected for the THF site. TwistAmp exo probes were purchased from LGC Biosearch Technologies (Petaluma, CA). Primers were developed manually to have the following characteristics: 30 to $70 \%$ GC content, runs of more than four identical nucleotides were avoided, secondary structures with a $\mathrm{T}_{\mathrm{m}}$ between 37 and $42^{\circ} \mathrm{C}$ were avoided, and primers were 30 to 35 nucleotides in length. RPA primers were purchased from SigmaAldrich (St. Louis, MO).

Simplex RPA assays optimization and sensitivity. Bacterial DNA was extracted from pure cultures of the following strains: $X$. gardneri strain 444, X. euvesicatoria strain 85-10, X. perforans strain 91-118, and $X$. vesicatoria strain MME. DNA was extracted both with the extraction buffer alone and in combination with boiling the cells in replicates of three. RPA was performed using the materials and protocols in the TwistAmp Exo kits (TwistDx Ltd.). The simplex master mix for each RPA assay contained $2.1 \mu \mathrm{l}$ of $10 \mu \mathrm{M}$ single forward primer, $2.1 \mu \mathrm{l}$ of $10 \mu \mathrm{M}$ single reverse primer, $0.6 \mu \mathrm{l}$ of $10 \mu \mathrm{M}$ single TwistAmp exo probe, $29.5 \mu \mathrm{l}$ of rehydration buffer, and $8.2 \mu \mathrm{l}$ of sterile deionized water. To rehydrate the dried TwistAmp Exo kit reaction pellets, $42.5 \mu \mathrm{l}$ of the master mix was added to each 0.2-ml reaction tube. Five microliters of DNA template and a single ATLAS Magnetic Micro Bearing Ball (TwistDx Ltd.) were added to each tube. The reaction mixture was mixed using a pipette, and $2.5 \mu \mathrm{l}$ of $280 \mathrm{mM}$ magnesium acetate was added to start the reaction. Fluorescence measurements of the FAM fluorophore were performed in an Axxin T8-ISO Isothermal Instrument (TwistDx Ltd.) every $10 \mathrm{~s}$ for up to $30 \mathrm{~min}$. To determine the optimal reaction temperature for each exo probe and primer set, RPA reactions were performed at $37,38,39,40,41$, and $42^{\circ} \mathrm{C}$. Optimal reaction conditions, time and temperature, were selected that resulted in the best amplification curve. Amplification curves that achieved the highest amplitude in the shortest time and were the most sigmoidal in shape were considered optimum.

The results from the optimization experiments were used to define the optimal reaction conditions that were used to determine the sensitivity of each RPA assay. To determine the sensitivity of each exo probe and primer set, bacterial suspensions of $X$. gardneri strain 444, X. euvesicatoria strain 85-10, X. perforans strain 91-118, and $X$. vesicatoria strain MME were prepared in the extraction buffer and adjusted to $A_{600}=0.3\left(\sim 5 \times 10^{8} \mathrm{CFU} / \mathrm{ml}\right)$ in replicates of three. The bacterial suspensions were serially diluted to $10^{1}$ CFU/ml. DNA was then extracted from each dilution using $200 \mu \mathrm{l}$ of extraction buffer alone and in combination with boiling the cells. Without disturbing the pellet formed after centrifugation, $5 \mu \mathrm{l}$ of each DNA extract was tested using the optimized RPA assay for each bacterial spot pathogen. Fluorescence measurements of the FAM fluorophore were performed in an Axxin T8-ISO Isothermal Instrument every $10 \mathrm{~s}$ for 25 (X. gardneri RPA assay) or $30 \mathrm{~min}(X$. euvesicatoria and $X$. perforans RPA assays) incubated at $41^{\circ} \mathrm{C}$.

Simplex RPA assays specificity and validation. To evaluate the specificity of each simplex RPA assay, each RPA assay analyzed DNA extracted from all of the bacterial spot strains listed in Table 1. In a previous study, Strayer et al. (2016) compared the $h r c N$ gene sequences of the four bacterial spot pathogens with other $h r c N$ gene sequences and additional sequenced genes in the NCBI database using the Standard Nucleotide BLAST (blastn suite) tool. Based on these results, $X$. axonopodis pv. citrumelo strain F1, $X$. citri subsp. citri strain 306, X. cynarae strain CFBP2044, and $X$. campestris pv. campestris strain 1574 were identified as potential plant pathogenic xanthomonads that could be amplified by one or more of the RPA assays. To evaluate the specificity of each assay, strains of all four of these Xanthomonas spp. were tested with each RPA assay. To verify the accuracy of each simplex RPA assay, DNA was extracted using the extraction buffer only method from 20 strains of $X$. gardneri, 19 strains of $X$. euvesicatoria, and 18 strains of $X$. perforans. Each DNA sample was evaluated for amplification with each RPA exo probe and primer pair.

Verification of simplex RPA assays for detection of bacterial spot xanthomonads in infected plant tissue in the laboratory. Two- to three-week old cultivar Bonnie Best tomato plants were inoculated with three strains (CFB2625, X47, and 0121) of $X$. gardneri, three strains (85-10, E3, and R10) of $X$. euvesicatoria, and three strains (91-118, GEV485, and ETH11) of $X$. perforans. The strains were grown on NA plates at $28^{\circ} \mathrm{C}$ for 24 h. Bacterial suspensions were prepared and adjusted to $A_{600}=0.3$ $\left(\sim 5 \times 10^{8} \mathrm{CFU} / \mathrm{ml}\right)$. Suspensions were sprayed onto abaxial and adaxial leaf surfaces of the tomato leaves. The inoculated plants were placed in clear plastic bags to maintain high humidity and incubated in a growth chamber at $28^{\circ} \mathrm{C}$ for $48 \mathrm{~h}$. The bags were then removed, and leaf samples with obvious lesions were collected $\sim 10$ days postinoculation. In addition, nine tomato fruits were collected from naturally infected tomato plants from field production areas in Ohio. Six tomato fruit, three tomato stems, and nine tomato leaf samples were also collected from naturally infected tomato plants from field production areas in Florida.

TABLE 2. TwistAmp recombinase polymerase amplification exo probes and primers designed and used in this study to amplify regions of the $h r c N$ of four pathogens (Xanthomonas euvesicatoria, X. gardneri, X. perforans, and X. vesicatoria) associated with bacterial spot

\begin{tabular}{|c|c|c|}
\hline Name & Sequence $^{\mathrm{a}}$ & $\mathrm{G}+\mathrm{C}(\%)$ \\
\hline$X$. gardneri exo probe & 5'-TCTCGCCTTGCTGGCGCCGTTTGGCGAGC-dT-FAM-HG-dT-BHQ1-GGGCTTGTCGCGC-3' & 69.6 \\
\hline XGF primerb ${ }^{b}$ & 5'-GCACGCTGTTGCAACGTGCCGAGGTGGTGG-3' & 66.7 \\
\hline XGR primer ${ }^{b}$ & 5'-CGTCCGCCGGCTCACCCAGGCCATCGAGTA-3' & 70.0 \\
\hline$X$. perforans exo probe & 5'-CGGGCAAGGAGCCATCGCCTGTGACACC-dT-FAM-GHG-dT-BHQ1-GCCGATCCAGGCG-3' & 69.6 \\
\hline FP1 primer ${ }^{\mathrm{c}}$ & 5'-GTTGGACCGGCCTTGCTGGGCCGCGTGCTC-3' & 73.3 \\
\hline RP1 primer ${ }^{c}$ & 5'-GTCGGCATGGGGTGTTCGATCAGCCGCCGA-3' & 66.7 \\
\hline$X$. vesicatoria exo probe ${ }^{\mathrm{d}}$ & 5'-GCCTTGCTGGCGCCGTTTGGCGAATTGG-dT-FAM-GHGG-dT-BHQ1-TGTCGCGCGAAA-3' & 63.0 \\
\hline
\end{tabular}


Verification of simplex RPA assay for detection of $X$. perforans in infected plant tissue in the field. Twelve leaf samples were collected from tomato plants artificially infected with $X$. perforans strain GEV485 from field production areas at the University of Florida North Florida Research and Education Center (NFREC) in Quincy, Florida. Ten leaf samples were collected from tomato plants artificially infected with four $X$. perforans strains (GEV904, GEV917, GEV1001, and GEV1063) from field production areas at the University of Florida Gulf Coast Research and Education Center (GCREC) in Wimauma, Florida. Twelve additional leaf samples were collected from naturally infected tomato plants from field production areas in Gadsden County, Florida and Decatur County, Georgia (six samples per production area). At each production location, DNA was extracted from each sample using the extraction buffer-only method and analyzed using the $X$. euvesicatoria pathovar exo probe and primer set (forward primer 1 and reverse primer 1). Fluorescence measurements of the FAM fluorophore were performed in an Axxin T8-ISO Isothermal Instrument powered by a PowerGorilla External Battery (TwistDx Ltd.) every $10 \mathrm{~s}$ for 30 min incubated at $41^{\circ} \mathrm{C}$. DNA extracted from $X$. perforans strain 91-118 was used as a positive control, and water and/or healthy tissue were used as nontemplate and negative controls, respectively.

\section{RESULTS}

Simplex RPA assays optimization and sensitivity. The aligned $h r c N$ sequences obtained from the NCBI database were used to create four RPA exo probes and three primer sets to detect $X$. euvesicatoria, $X$. gardneri, $X$. perforans, and $X$. vesicatoria (Table 2). For the $X$. gardneri RPA assay, the exo probe and primer set only amplified DNA extracted from $X$. gardneri strain 444 and did not amplify DNA from the other three bacterial species (Table 1). Additionally, reactions incubated at $41^{\circ} \mathrm{C}$ with a reaction time of 25 min resulted in the best amplification curves (Fig. 1A).
These optimal reaction conditions were used for determining the sensitivity of the $X$. gardneri exo probe and primer set. The detection limit of the $X$. gardneri RPA assay was $5 \times 10^{6} \mathrm{CFU} / \mathrm{ml}$ (Table 3), corresponding to $\sim 5,000$ bacterial cells in the RPA reaction mixture $\left(10^{6} \mathrm{CFU} / \mathrm{ml} \times 5 \mu \mathrm{l} \times 1 \mathrm{ml} / 1,000 \mu \mathrm{l}\right)$. When comparing the two DNA extraction methods, both resulted in similar detection limits and specificity of this RPA assay (data not shown). However, the extraction buffer-only method was more rapid and chosen as the optimal DNA extraction method from pure cultures for the $X$. gardneri RPA assay.

For the $X$. euvesicatoria RPA assay, the exo probe and primer set amplified DNA extracted from both $X$. euvesicatoria strain 85-10 and $X$. perforans strain 91-118 and did not amplify DNA from the other two bacterial species (Table 1). Additionally, reactions incubated at $41^{\circ} \mathrm{C}$ with a reaction time of 30 min resulted in the best amplification curves (Fig. 1B). These optimal reaction conditions were used for determining the sensitivity of the $X$. euvesicatoria exo probe and primer set. The $X$. euvesicatoria RPA assay detected DNA extracted from bacterial suspension concentrations of either X. euvesicatoria strain 85-10 or X. perforans strain 91-118 ranging from $10^{6}$ to $10^{8} \mathrm{CFU} / \mathrm{ml}$ (Table 3 ). The detection limit of the $X$. euvesicatoria assay was $5 \times 10^{6} \mathrm{CFU} / \mathrm{ml}$, corresponding to $\sim 5,000$ bacterial cells in the RPA reaction mixture $\left(10^{6} \mathrm{CFU} / \mathrm{ml} \times 5 \mu \mathrm{l} \times 1 \mathrm{ml} / 1,000 \mu \mathrm{l}\right)$. When comparing the two DNA extraction methods, neither extraction method affected detection limits or the specificity of this RPA assay (data not shown). However, the extraction buffer-only method was more rapid, and it was chosen as the optimal DNA extraction method from pure cultures for the $X$. euvesicatoria RPA assay.

For the $X$. perforans RPA assay, the exo probe and primer set only amplified DNA extracted from $X$. perforans strain 91-118, but it did not amplify DNA from the other three bacterial species (Table 1). Additionally, reactions incubated at $41^{\circ} \mathrm{C}$ with a reaction time of $30 \mathrm{~min}$ resulted in the best amplification curves (Fig. 1C). These

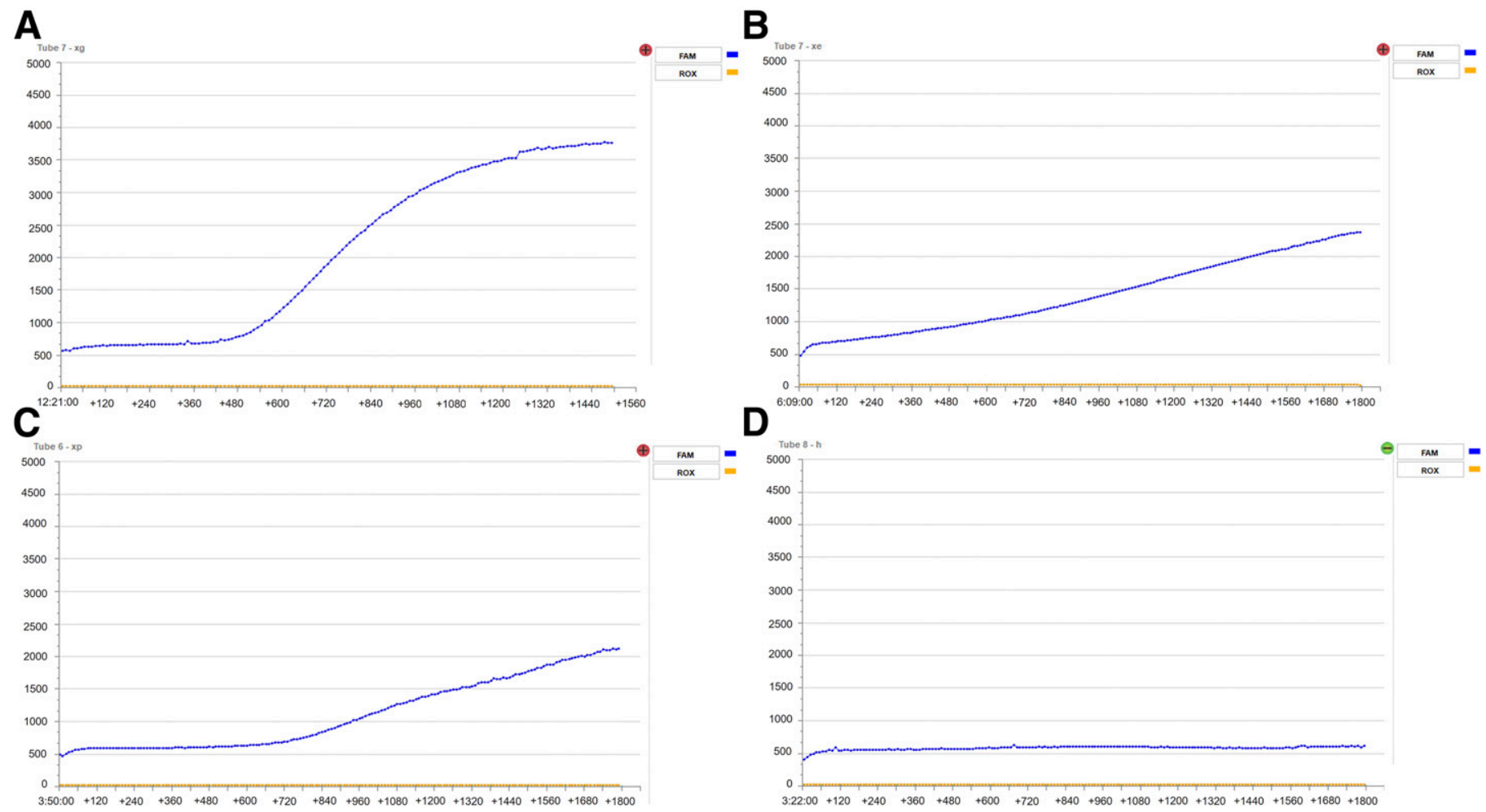

Fig. 1. Amplification curves for recombinase polymerase amplification (RPA) reactions incubated at $41^{\circ} \mathrm{C}$ (optimal reaction temperature) displayed using the Axxin T8-ISO Isothermal Instrument desktop application. A, DNA extracted from Xanthomonas gardneri strain 444 amplified by the X. gardneri RPA exo probe and primer set. B, DNA extracted from X. euvesicatoria strain 85-10 amplified by the X. euvesicatoria pathovar RPA exo probe and primer set. C, DNA extracted from $X$. perforans strain 91-118 amplified by the $X$. perforans RPA exo probe and primer set. D, An example of negative RPA result (no amplification) using water and the $X$. euvesicatoria RPA exo probe and primer set. FAM = test channel to detect probes labeled the reporter dye FAM. ROX $=$ control channel to detect probes labeled the reporter dye ROX, if present. 
optimal reaction conditions were used for determining the sensitivity of the $X$. perforans exo probe and primer set. The detection limit of the $X$. perforans assay was $5 \times 10^{7} \mathrm{CFU} / \mathrm{ml}$ (Table 3), corresponding to $\sim 50,000$ bacterial cells in the RPA reaction mixture $\left(10^{7} \mathrm{CFU} / \mathrm{ml} \times 5 \mu \mathrm{l} \times 1 \mathrm{ml} / 1,000 \mu \mathrm{l}\right)$. When comparing the two DNA extraction methods, both extraction methods resulted in the same detection limits and specificity of this RPA assay (data not shown). However, the extraction buffer-only method was more rapid and chosen as the optimal DNA extraction method from pure cultures for the $X$. perforans RPA assay. Additionally, Supplementary Figure S1 displays the amplification curves of DNA extracted from $X$. perforans strain 91-118 with each RPA probe and primer sets specific for the $X$. euvesicatoria pathovars, $X$. gardneri, and $X$. perforans.

For the $X$. vesicatoria RPA assay, the exo probe and primer set did not amplify DNA extracted from any of the bacterial spot pathogens following protocols outlined in the TwistAmp Exo kits (data not shown). No optimal combination of reaction temperature, reaction time, and extraction method could be determined. Different exo probe and primer concentrations were also evaluated in the hopes of yielding a positive result from DNA extracted from $X$. vesicatoria strain MME. Using a master mix containing $0.6 \mu \mathrm{l}$ of $20 \mu \mathrm{M} X$. vesicatoria exo probe, the RPA assay amplified DNA extracted from $X$. vesicatoria strain MME. However, amplification was not reproducible, and the results could not be validated. Because of exo probe and primer design restrictions (TwistDx 2017), alternative sequences could not be identified within the $h r c N$.

Simplex RPA assays specificity and validation. All DNA samples extracted from 20 strains of $X$. gardneri, 18 strains of $X$. euvesicatoria, and 18 strains of $X$. perforans tested positive for their respective assays (Table 1 ). The $X$. euvesicatoria RPA assay amplified DNA extracted from all strains belonging to $X$. euvesicatoria and $X$. perforans. In contrast, the $X$. perforans RPA assay only amplified DNA extracted from the 18 strains of $X$. perforans. Additionally, the $X$. gardneri RPA assay only amplified DNA extracted from the $20 X$. gardneri strains.

To determine specificity of each RPA assay, $X$. axonopodis pv. citrumelo strain F1, X. citri subsp. citri strain $306, X$. campestris $\mathrm{pv}$. campestris strain 1574, and X. cynarae strain CFB2044 were tested with the $X$. gardneri, $X$. euvesicatoria, and $X$. perforans RPA assays (Table 4). DNA extracted from X. cynarae strain CFBP2044 was only amplified by $X$. gardneri exo probe and primer set. $X$. axonopodis pv. citrumelo strain F1 was amplified by both $X$. euvesicatoria and $X$. perforans exo probe and primer sets. However, none of the RPA exo probes and primer sets for the bacterial spot xanthomonads amplified DNA extracted from $X$. campestris pv. campestris strain 1574 or X. citri subsp. citri strain 306.

Evaluation of simplex RPA analysis in the laboratory with artificially inoculated plant tissue. All of the DNA that was extracted directly from 54 leaf lesions collected from artificially inoculated tomato leaves was positive for one of three bacterial spot pathogens (Table 5). The X. gardneri exo probe and primer set only amplified DNA extracted from leaf lesions sampled from tomato plants inoculated with $X$. gardneri strains. In contrast, the $X$. euvesicatoria exo probe and primer set amplified DNA extracted from leaf lesions sampled from plants inoculated with either $X$. euvesicatoria or $X$. perforans strains. Although $X$. perforans was isolated from leaf lesions, the $X$. perforans exo probe and primer set did not amplify DNA extracted from leaf lesions sampled from tomato plants inoculated with strains of $X$. perforans. Because the X. perforans exo probe and primer set did not amplify DNA extracted from infected plant tissue, the $X$. perforans assay could only be used to analyze DNA extracted

TABLE 3. Sensitivity of simplex (single reaction with one probe and primer set) recombinase polymerase amplification (RPA) assays using the Xanthomonas gardneri exo probe and primer set (XGF and XGR), the X. euvesicatoria exo probe and primer set (forward primer 1 [FP1] and reverse primer 1 [RP1]), the $X$. perforans exo probe and primer set (FP1 and RP1), or the X. vesicatoria exo probe and primer set (XVF and XVR)

\begin{tabular}{|c|c|c|c|}
\hline Probe and primers & Species and strain $(\mathrm{s})^{\mathrm{a}}$ & $\begin{array}{c}\text { Detection limit } \\
{\text { (colony-forming units per milliliter })^{\mathrm{b}}}\end{array}$ & Reaction $^{\mathrm{c}}$ \\
\hline$X$. gardneri exo probe, $\mathrm{XGF}$, and XGR & $X$. gardneri strain 444 & $5 \times 10^{6}$ & + \\
\hline X. euvesicatoria exo probe, FP1, and RP1 & $\begin{array}{l}X \text {. euvesicatoria strain } 85-10, X \text {. perforans } \\
\text { strain } 91-118\end{array}$ & $5 \times 10^{6}$ & + \\
\hline$X$. perforans exo probe, FP1, and RP1 & $X$. perforans strain $91-118$ & $5 \times 10^{7}$ & + \\
\hline$X$. vesicatoria exo probe, $\mathrm{XVF}$, and XVR & $X$. vesicatoria strain $\mathrm{MME}$ & ND & ND \\
\hline
\end{tabular}

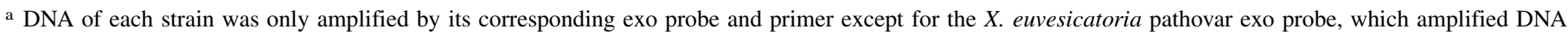
extracted from both strains of $X$. euvesicatoria and $X$. perforans.

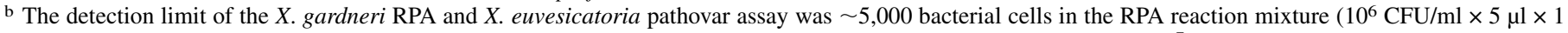
$\mathrm{ml} / 1,000 \mu \mathrm{l})$. The detection limit of the $X$. perforans assay was $\sim 50,000$ bacterial cells in the $\mathrm{RPA}$ reaction mixture $\left(10^{7} \mathrm{CFU} / \mathrm{ml} \times 5 \mu \mathrm{l} \times 1 \mathrm{ml} / 1,000 \mu \mathrm{l}\right) . \mathrm{ND}=$ not determined.

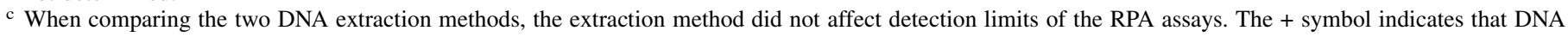
extracted from the pure culture of the strain was amplified by the RPA exo probe and primer set for X. euvesicatoria, X. gardneri, X. perforans, and/or X. vesicatoria.

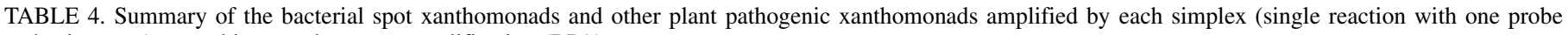
and primer set) recombinase polymerase amplification (RPA) assay

\begin{tabular}{|c|c|c|c|}
\hline Species and strain(s) & $\begin{array}{l}\text { Reaction with Xanthomonas gardneri } \\
\text { exo probe, XGF, and XGR }{ }^{\mathrm{a}}\end{array}$ & $\begin{array}{l}\text { Reaction with } X \text {. euvesicatoria } \\
\text { pathovar exo probe, FP1, and RP1 }\end{array}$ & $\begin{array}{c}\text { Reaction with } X \text {. perforans exo } \\
\text { probe, FP1, and RP1 }\end{array}$ \\
\hline$X$. axonopodis pv. citrumelo strain F1 & - & + & + \\
\hline X. campestris pv. campestris strain 1574 & - & - & - \\
\hline$X$. citri subsp. citri strain 306 & - & - & - \\
\hline X. cynarae strain CFBP2044 & + & - & - \\
\hline X. euvesicatoria strain $85-10$ & - & + & - \\
\hline$X$. gardneri strain 444 & + & - & - \\
\hline$X$. perforans strain $91-118$ & - & + & + \\
\hline$X$. vesicatoria strain $\mathrm{MME}$ & - & - & - \\
\hline
\end{tabular}


from pure cultures. When comparing the two DNA extraction methods, the extraction method did not affect the ability of the RPA assays to amplify DNA extracted from their targeted species (data not shown). However, the extraction buffer-only method was more rapid, and it was chosen as the optimal method to extract DNA from infected plant tissue for X. gardneri and X. euvesicatoria RPA assays.

Evaluation of simplex RPA analysis in the laboratory with naturally infected plant tissue. Using the extraction buffer-only method, six of nine tomato fruits collected from field production areas in Ohio tested positive for X. gardneri (Table 6). After isolation from all lesions, nine pure cultures were obtained, but only six cultures from the six RPA-positive fruit lesions had colony morphological characteristics typical of xanthomonads, whereas the other three did not produce typical yellow colonies (Doidge 1921; Potnis et al. 2015). DNA was extracted from all nine pure cultures, but the $X$. gardneri RPA exo probe and primer set only amplified the DNA that was extracted from the six pure cultures that produced yellow colonies typical of the genus Xanthomonas (Table 6). The six positive pure cultures were isolated from the six tomato fruits for $X$. gardneri. Additionally, all DNA samples extracted from lesions of naturally infected tomato fruit, stem, and leaf tissue collected from field production areas in Florida were amplified by the $X$. euvesicatoria exo probe and primer set (Table 6). After isolation from all lesions, pure cultures were obtained that were typical of xanthomonads. DNA was extracted from pure cultures and amplified by both $X$. perforans and $X$. euvesicatoria RPA exo probes and primers (Table 6).

Evaluation of simplex RPA analysis of bacterial spot lesions in the field. The $X$. euvesicatoria pathovar RPA assay was conducted in the field using the Axxin T8-ISO Isothermal Instrument powered by a PowerGorilla External Battery (Fig. 2).
All DNA samples extracted from lesions of artificially infected tomato leaf tissue collected from field production areas at the NFREC and the GCREC were amplified by the $X$. euvesicatoria exo probe and primer set (Table 7). DNA samples that were extracted from pure cultures isolated from the RPA-sampled lesions were amplified by both $X$. perforans and $X$. euvesicatoria exo probes and primers. Because the pure cultures from these samples were amplified by the $X$. perforans-specific exo probe, all 22 of the plant samples were infected with $X$. perforans; nine of 12 DNA samples extracted from lesions of naturally infected tomato leaf tissue collected from field production areas in Decatur County, Georgia (five positive) and Gadsden County, Florida (four positive) counties were amplified by the $X$. euvesicatoria exo probe and primer set (Table 7). After isolation from all lesions, 12 pure cultures were obtained; however, only nine cultures from the RPA-positive fruit lesions had colony morphological characteristics typical of xanthomonads, whereas the other three did not produce typical yellow colonies (Doidge 1921; Potnis et al. 2015). DNA samples that were extracted from the nine pure cultures that produced yellow colonies typical of the genus Xanthomonas were amplified by both $X$. perforans and $X$. euvesicatoria RPA exo probes and primers, which confirmed the $X$. euvesicatoria RPA results of the DNA extracted directly from the infected tissue in the field (Table 7). Because these samples were amplified by the $X$. perforans-specific exo probe, $X$. perforans was identified as the causal agent of the bacterial spot symptoms in the nine positive plant samples.

\section{DISCUSSION}

In this study, four RPA assays were designed and analyzed for the detection of the four Xanthomonas spp. that cause bacterial spot of tomato (Supplementary Table S1). Each RPA assay was designed

TABLE 5. Recombinase polymerase amplification (RPA) results in the laboratory for DNA extracted from leaf lesions were sampled from artificially inoculated tomato tissue and pure cultures after isolation

\begin{tabular}{|c|c|c|c|c|}
\hline No. of samples & Inoculated species ${ }^{\mathrm{a}}$ & Simplex ${ }^{b}$ RPA assay & No. of positive lesion DNA samples ${ }^{c}$ & No. of positive culture DNA samples ${ }^{\mathrm{c}}$ \\
\hline 18 & Xanthomonas gardneri & $X$. gardneri & 18 & 18 \\
\hline 18 & X. gardneri & X. euvesicatoria & 0 & 0 \\
\hline 18 & X. gardneri & $X$. perforans & 0 & 0 \\
\hline 18 & X. euvesicatoria & X. euvesicatoria & 18 & 18 \\
\hline 18 & X. euvesicatoria & $X$. perforans & 0 & 0 \\
\hline 18 & $X$. perforans & X. gardneri & 0 & 0 \\
\hline 18 & X. perforans & X. euvesicatoria & 18 & 18 \\
\hline
\end{tabular}

a Two- to three-week-old cultivar Bonnie Best tomato plants were individually inoculated with one of three $X$. gardneri strains (CFB2625, X47, and 0121), three $X$. euvesicatoria strains (85-10, E3, and R10), or three X. perforans strains (strains 91-118, GEV485, and ETH11). Lesions that developed were sampled 5 days after inoculation. There was a total of six leaf samples per strain.

b Simplex RPA assay is defined as an RPA assay containing a single reaction with one probe and primer set.

${ }^{c}$ Pure cultures were isolated from the same bacterial spot lesions that were analyzed.

TABLE 6. Recombinase polymerase amplification (RPA) results in the laboratory for DNA extracted from leaf and fruit lesions collected from naturally infected tomato tissue and for pure cultures isolated from the lesions after isolation in the laboratory

\begin{tabular}{lllcc}
\hline No. of samples & Location and tissue type & Simplex RPA assay & No. of positive lesion DNA samples & No. of positive culture DNA samples $^{\mathrm{b}}$ \\
\hline 9 & Ohio, fruit & Xanthomonas gardneri & 6 & 6 \\
9 & Ohio, fruit & X. euvesicatoria & 0 & 0 \\
9 & Ohio, fruit & X. perforans & Not tested & 0 \\
6 & Florida, fruit & X. gardneri & 0 & 0 \\
6 & Florida, fruit & X. euvesicatoria & 6 & 6 \\
6 & Florida, fruit & X. perforans & Not tested & 6 \\
3 & Florida, stem & X. gardneri & 3 & 0 \\
3 & Florida, stem & X. euvesicatoria & Not tested & 3 \\
3 & Florida, stem & X. perforans & 0 & 3 \\
9 & Florida, leaf & X. gardneri & 9 & 0 \\
9 & Florida, leaf & X. euvesicatoria & Not tested & 9 \\
9 & Florida, leaf & X. perforans & 9 \\
\hline
\end{tabular}

a Simplex RPA assay is defined as an RPA assay containing a single reaction with one probe and primer set.

b Pure cultures were isolated from the same bacterial spot lesions that were analyzed. 
to target a region of the $h r c N$ of $X$. euvesicatoria, $X$. gardneri, $X$. perforans, or X. vesicatoria. Strayer et al. (2016) showed that the $h r c N$ gene sequences for each bacterial spot species are different from the $h r c N$ sequences of most of the other plant pathogenic xanthomonads. Thus, the $h r c N$ region has been useful in differentiating the four bacterial spot pathogens in the past (Leite et al. 1994; Obradovic et al. 2004; Strayer et al. 2016). The X. gardneri RPA assay only amplified DNA extracted from strains of $X$. gardneri and did not amplify DNA from the other bacterial spot pathogens. However, it did amplify DNA extracted from $X$. cynarae, which causes a bacterial spot disease of artichokes (Trébaol et al. 2001). This reaction was expected, because $X$. cynarae seems to be synonymous with $X$. gardneri based on MLSA results using sequences from four housekeeping genes (Young et al. 2008); furthermore, Young et al. (2008) have recommended combining $X$. gardneri and $X$. cynarae into a single species. Because the
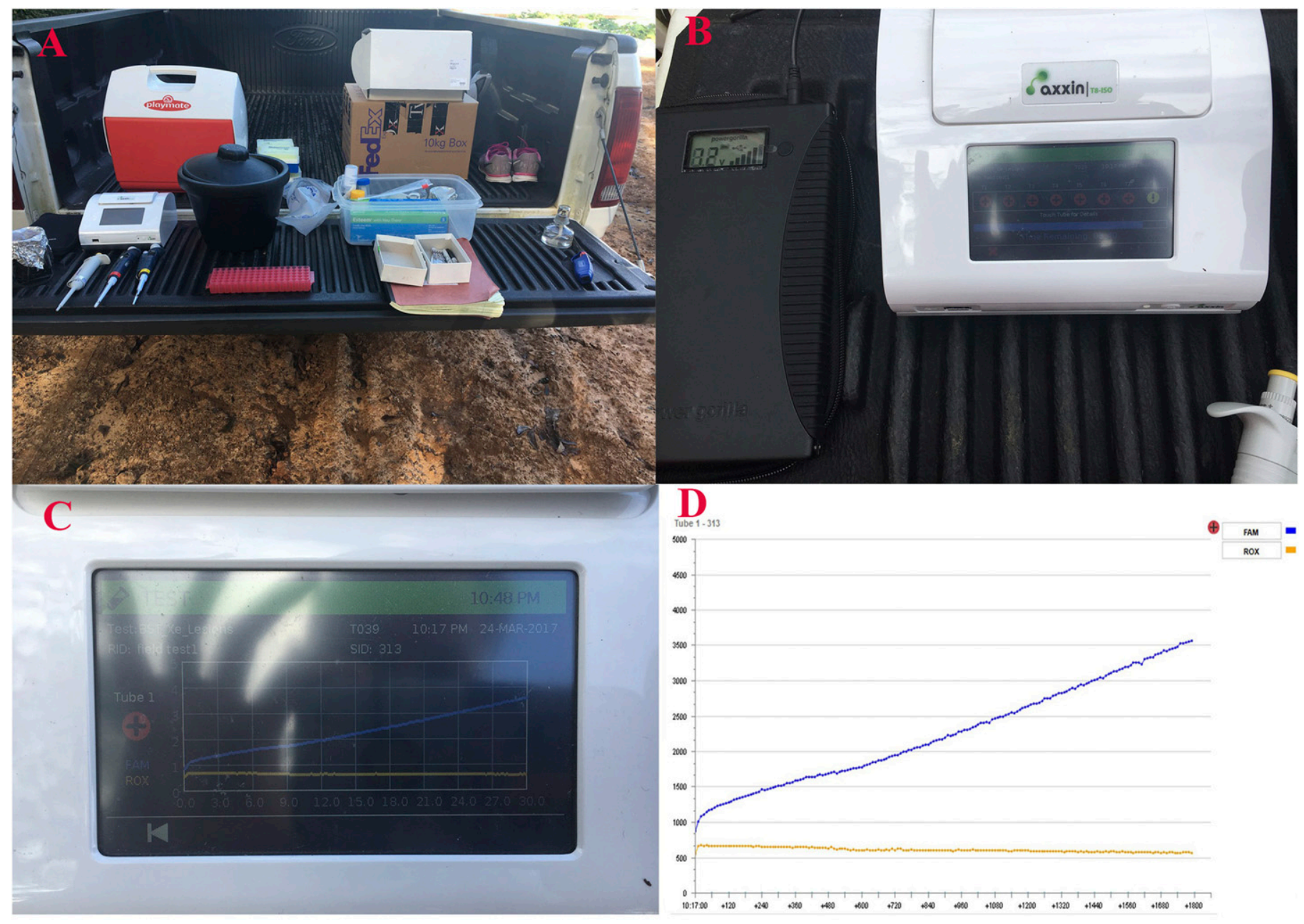

Fig. 2. Field test of the Xanthomonas euvesicatoria recombinase polymerase amplification (RPA) assay using the Axxin T8-ISO Isothermal Instrument powered by a PowerGorilla External Battery. A, Equipment used in the field test of the X. euvesicatoria pathovar RPA assay. B, The Axxin T8-ISO Isothermal Instrument powered by a PowerGorilla External Battery. C, A positive reaction result displayed on the Axxin T8-ISO Isothermal Instrument touchscreen. D, A positive reaction result displayed using the Axxin T8-ISO Isothermal Instrument desktop application. FAM = test channel to detect probes labeled the reporter dye FAM. $\mathrm{ROX}=$ control channel to detect probes labeled the reporter dye ROX, if present.

TABLE 7. Recombinase polymerase amplification (RPA) results for DNA extracted from leaf and fruit lesions collected from infected tomato tissue in the field and pure cultures after isolation from RPA-sampled lesions in the laboratory

\begin{tabular}{lllcr}
\hline No. of samples & Location and tissue type & Simplex RPA assay & No. of positive lesion DNA samples $^{\mathrm{c}}$ & No. of positive culture DNA samples $^{\mathrm{c}}$ \\
\hline 12 & NFREC, leaf & Xanthomonas gardneri & 12 & 12 \\
12 & NFREC, leaf & X. euvesicatoria & Not tested & 12 \\
10 & GCREC, leaf & X. euvesicatoria & 10 & 10 \\
10 & GCREC, leaf & X. perforans & Not tested & 4 \\
6 & Florida, leaf & X. euvesicatoria & Not tested & 4 \\
6 & Florida, leaf & X. perforans & 5 & 4 \\
6 & Georgia, leaf & X. euvesicatoria & Not tested & 5 \\
6 & Georgia, leaf & X. perforans & 5 \\
\hline
\end{tabular}

a Twelve leaf samples were collected from artificially infected tomato plants at the University of Florida North Florida Research and Education Center (NFREC) in Quincy, Florida. Ten leaf samples were collected from artificially infected tomato plants at the University of Florida Gulf Coast Research and Education Center (GCREC) in Wimauma, Florida. The remaining 12 samples were collected from naturally infected tomato plants from commercial production areas in Gadsden County, Florida and Decatur County, Georgia.

b Simplex RPA assay is defined as an RPA assay containing a single reaction with one probe and primer set.

${ }^{c}$ DNA was extracted from leaf lesions and analyzed on location in each tomato production area. Pure cultures were isolated from the same bacterial spot lesions that were analyzed. After isolation, DNA was extracted from pure cultures and analyzed in the laboratory. 
taxonomy for these two species will be modified in the near future, it is highly beneficial that the $X$. gardneri assay can detect strains from both species. Furthermore, the $X$. gardneri exo probe and primer set did not amplify DNA extracted from the other plant pathogenic xanthomonads tested in this study. The $X$. gardneri RPA assay was also able to amplify DNA extracted from 20 different $X$. gardneri strains isolated from Costa Rica, France, Hungary, Pennsylvania, and South Africa. These results show that the $X$. gardneri exo probe and primer set is not region specific and that this RPA assay could be utilized worldwide. Additionally, the $X$. gardneri RPA assay was also able to detect bacterial DNA extracted from leaf and fruit lesions collected from tomato plants infected artificially and naturally with $X$. gardneri.

Although the $h r c N$ region has been useful in differentiating Xanthomonas species, X. euvesicatoria and X. perforans are closely related species based on the $h r c N$ gene sequence in which they only varied by two single-nucleotide polymorphisms (SNPs) (Strayer et al. 2016). In this study, both $X$. perforans and $X$. euvesicatoria exo probes were designed to target the two SNPs in the $h r c N$ sequence. Through targeting these SNPs, the $X$. perforans exo probe and primer set only amplified DNA extracted from strains of $X$. perforans. Unfortunately, the $X$. perforans exo probe and primer set also amplified DNA extracted from the $X$. axonopodis $\mathrm{pv}$. citrumelo strain. Although it is closely related to $X$. euvesicatoria and $X$. perforans based on the $h r c N$ gene, $X$. axonopodis $\mathrm{pv}$. citrumelo causes a bacterial spot disease of citrus, but it has a completely different host range (Jalan et al. 2011). Because $X$. axonopodis pv. citrumelo only infects a few citrus varieties (Graham et al. 1990), it is unlikely that it would be isolated from tomato, and it is not a major concern for this assay. Additionally, the $X$. perforans exo probe and primer set amplified DNA extracted from 18 different $X$. perforans strains isolated from 11 distinct geographic regions. Similar to the $X$. gardneri RPA assay results, the $X$. perforans exo probe and primer set is not specific to particular geographical region and could be utilized worldwide. Although it was unable to amplify DNA extracted from leaf lesions infected with $X$. perforans, it could still be used to detect $X$. perforans in culture.

In contrast, the $X$. euvesicatoria exo probe was unable to differentiate $X$. euvesicatoria from $X$. perforans. It amplified DNA extracted from all of the strains of $X$. euvesicatoria and $X$. perforans that were tested in this study. This assay is not region specific, because the $X$. euvesicatoria exo probe and primer set amplified DNA extracted from 37 different $X$. euvesicatoria and $X$. perforans strains isolated from 17 different geographic regions. Constantin et al. (2016) determined that $X$. perforans is synonymous with $X$. euvesicatoria based on MLSA results using seven genes, average nucleotide identity (ANI) values, DNA-DNA hybridization data, and phenotypic characteristics. Based on these results, they proposed that the taxonomy of $X$. euvesicatoria and $X$. perforans should be changed to $X$. euvesicatoria pv. euvesicatoria and $X$. euvesicatoria pv. perforans, respectively. Additionally, Barak et al. (2016) showed that $X$. euvesicatoria and $X$. perforans share an ANI value of $>99 \%$ by whole-genome sequencing and should be considered as a single species. Because the $X$. euvesicatoria exo probe and primer set can detect both $X$. euvesicatoria and $X$. perforans from crude plant samples, it would be beneficial for bacterial spot disease diagnosis, especially in Florida. In Florida, $X$. perforans is the dominant species associated with the disease on tomato, whereas $X$. euvesicatoria is primarily associated with the disease on pepper (Horvath et al. 2012; Potnis et al. 2015). Bacterial spot leaf lesions can be easily confused with symptoms of bacterial speck, early blight, gray leaf spot, and target spot (Momol et al. 2008). The $X$. euvesicatoria RPA assay could be used to diagnose bacterial spot of tomato in the field in as little as $45 \mathrm{~min}$. This would allow producers to make disease management decisions rapidly and efficiently. However, if differentiating $X$. perforans from $X$. euvesicatoria is required, then bacteria can be isolated from infected plant tissue and analyzed using the $X$. perforans exo probe and primer set in the laboratory. The $X$. euvesicatoria exo probe and primer set also amplified DNA extracted from the $X$. axonopodis pv. citrumelo strain. However, as previously stated, it is unlikely that $X$. axonopodis pv. citrumelo would be isolated from tomato, and it is not a major concern for this assay (Graham et al. 1990; Jalan et al. 2011).

An additional RPA exo probe and primer set was also designed to target the $h r c N$ gene sequence of $X$. vesicatoria. Although several reaction temperatures, time lengths, and extraction methods were evaluated, the $X$. vesicatoria exo probe and primer set was unable to amplify DNA extracted from pure cultures of $X$. vesicatoria following TwistAmp Exo kits protocols. Although amplification was achieved in a single reaction using a master mix containing $0.6 \mu \mathrm{l}$ of $20 \mu \mathrm{M} \mathrm{X}$. vesicatoria exo probe, amplification was not reproducible, and the results could not be validated. Unfortunately, alternative target sequences have not been identified within the $h r c N$ because of the restrictions in design considerations outlined in TwistDx (2017). Although it would have been beneficial to have an RPA exo probe and primer set for each bacterial spot pathogen, $X$. vesicatoria seems to be less prevalent in tomato production regions and could be considered as the least important Xanthomonas species currently associated with bacterial spot of tomato (Potnis et al. 2015). Historically, X. euvesicatoria and X. vesicatoria have had a worldwide distribution, but the other two species have increased in abundance in several tomato-growing regions and countries (Potnis et al. 2015). In this study, we designed two RPA assays that can detect DNA extracted directly from plant tissue infected with $X$. euvesicatoria, $X$. gardneri, and $X$. perforans. Thus, these two assays can be used to detect the most prevalent Xanthomonas spp. associated with bacterial spot of tomato in the field.

In addition to infected plant material, seed can serve as important source of inoculum for bacterial spot, especially in transplant production facilities (Jones et al. 1986; Pohronezny et al. 1992; Potnis et al. 2015). Dilution plating seed washings onto semiselective media containing Tween 80 is widely used for detecting plant pathogenic xanthomonads on seeds (Koenraadt et al. 2009; McGuire et al. 1986; Potnis et al. 2015). However, additional diagnostic methods, such as PCR and pathogenicity assays, are required to identify the species (Koenraadt et al. 2009; Leite et al. 1995). Thus, the need for a rapid and reliable seed detection for the bacterial spot pathogens would be useful for managing the disease. Leite et al. (1995) used PCR primers designed to amplify regions of the $h r p B$ followed by REA of PCR amplification products to detect and identify the bacterial spot pathogen $X$. campestris pv. vesicatoria from washings of naturally and artificially infected tomato and pepper seeds. Of the seed lots tested, the total bacterial population on naturally infected tomato and pepper seeds ranged from $0.8 \times 10^{2}$ to $1.1 \times 10^{7} \mathrm{CFU} / \mathrm{g}$ of seed, with the majority of seed lots containing $<5 \times 10^{3} \mathrm{CFU} / \mathrm{g}$ of seed (Leite et al. 1995). Thus, bacterial populations on tomato and pepper seeds are very low. Although these RPA assays work well for testing pure cultures and infected plant tissue, we do not believe that these RPA assays would be the ideal candidate for seed testing, and this was not an objective of this study. However, the development of a new RPA assay for the detection of the bacterial spot pathogens in seed could be done in the future.

RPA has several advantages over other detection methods that are currently used to diagnose bacterial spot of tomato. The RPA assays presented in this study only require incubation times of 25 to $30 \mathrm{~min}$ and a single reaction temperature of $41^{\circ} \mathrm{C}$ for DNA amplification in contrast to conventional and real-time PCRs, which require thermal cycle steps at higher temperatures and longer reaction times of at least 45 min (Obradovic et al. 2004; Strayer et al. 2016). Because RPA operates at a single reaction temperature, portable heating devices can be used to achieve amplification. The Axxin T8-ISO Isothermal Instrument (TwistDx Ltd.) used in this study was 
purchased for $<\$ 4,500$ and has an external rechargeable battery. Because an external rechargeable battery can be used, it is more mobile than conventional and real-time PCR instruments. This is also an advantage in places where equipment failures can occur because of power outages (Silva et al. 2015). In contrast, conventional and real-time PCR assays must be conducted in the laboratory, which requires the shipment of samples to diagnostic clinics for processing, and sample quality can be an issue. The $X$. gardneri and X. euvesicatoria RPA assays can be used on location in tomato production areas and provide tomato producers with a diagnosis in as little as $45 \mathrm{~min}$. These two RPA assays detected DNA extracted from plant tissue infected with $X$. euvesicatoria, $X$. gardneri, or $X$. perforans. In general, RPA assays can amplify DNA extracted from crude plant samples, because they are less sensitive to inhibitors, unlike conventional and real-time PCRs, that are present in plant tissue (Bessetti 2007; Hoy et al. 2001; Kim and Easley 2011; Palacio-Bielsa et al. 2011).

RPA also has some advantages over other isothermal amplification methods, such as loop-mediated isothermal amplification (LAMP), that can also be used to detect plant pathogens (Kubota et al. 2008; Temple and Johnson 2011; Yasuhara-Bell et al. 2013). In contrast to RPA, LAMP requires four to six primers and higher reaction temperatures of 60 to $65^{\circ} \mathrm{C}$ for DNA amplification (Kim and Easley 2011; Zanoli and Spoto 2012). Because RPA can operate at lower temperatures, it requires less energy to operate than LAMP and other higher-temperature isothermal amplification methods (Zanoli and Spoto 2012). RPA is also more tolerant to temperature fluctuations than LAMP, which makes it a great candidate for in-field diagnostics, where temperature control can be a challenge (Zanoli and Spoto 2012). Because the amplification product of LAMP is not easily degraded, the risk of carryover contamination and false positives is high, unlike in RPA (Dhama et al. 2014; Zanoli and Spoto 2012). Thus, RPA is an ideal isothermal amplification method for the detection of plant pathogens from plant tissue in the field.

The use of RPA to detect plant pathogens is a relatively novel concept. To our knowledge, there are only two other published RPA assays that utilize TwistAmp exo probes to detect plant viruses (Babu et al. 2017; Silva et al. 2015). Additionally, there are commercially available RPA assays for Xylella fastidiosa, Clavibacter michiganensis subsp. michiganensis, C. michiganensis subsp. sepedonicus, and Banana Bunchy Top Virus (Agdia Inc.). Some preliminary research on the use of recombinase polymerasebased assays was also conducted for the detection of Pseudomonas syringae pv. actinidiae and Rathayibacter toxicus in plant tissue (Arif et al. 2016; Stack et al. 2016). However, the three real-time RPA assays for X. euvesicatoria, X. gardneri, and X. perforans described in this study are the first to be designed and confirmed to detect one or multiple bacterial plant pathogens in the field. These three RPA assays are rapid, accurate, portable, and reproducible. Our novel assays will allow diagnosticians to easily and quickly identify the three most prominent bacterial spot pathogens from pure cultures and/or infected tissue. These RPA assays have the potential to aid plant pathologists and are an improvement over the current time-consuming identification techniques available for bacterial spot of tomato caused by $X$. euvesicatoria, X. gardneri, and $X$. perforans.

\section{ACKNOWLEDGMENTS}

We thank S. A. Miller from The Ohio State University for providing us with tomato fruit symptomatic with bacterial spot for recombinase polymerase amplification testing. We thank G. V. Minsavage, Y. Y. Liao, Q. Fan, G. E. Vallad, J. H. Freeman, and R. E. Stall for the technical support in conducting experiments. We also thank the following researchers for providing some of the Xanthomonas strains used in this study: D. A. Cuppels (Agriculture and Agri-Food Canada), M. Kebede (Haramaya University), S. Kim (Division of Plant Health, Pennsylvania Department of Agriculture), and S. A. Miller (The Ohio State University).

\section{LITERATURE CITED}

Alfano, J. R., and Collmer, A. 2004. Type III secretion system effector proteins: Double agents in bacterial disease and plant defense. Annu. Rev. Phytopathol. 42:385-414.

Araújo, E. R., Costa, J. R., Ferreira, M. A. S. V., and Quezado-Duval, A. M. 2012. Simultaneous detection and identification of the Xanthomonas species complex associated with tomato bacterial spot using species-specific primers and multiplex PCR. J. Appl. Microbiol. 113:1479-1490.

Arif, M., Busot, G., Mann, R., Rodoni, B., and Stack, J. 2016. Detection of the select agent Rathayibacter toxicus using recombinase polymerase amplification coupled with a lateral flow device. 2016 APS Annual Meeting. Retrieved 26 Apr 2018 from https://www.apsnet.org/meetings/Documents/ 2016_meeting_abstracts/aps2016_780.htm

Babu, B., Washburn, B. K., Sarigul Ertek, T., Miller, S. H., Riddle, C. B., Knox, G. W., Ochoa-Corona, F. M., Olson, J., Katircioglu, Y. Z., and Paret, M. L. 2017. A field based detection method for Rose rosette virus using isothermal probe based reverse transcription-recombinase polymerase amplification assay. J. Virol. Methods 247:81-90.

Barak, J. D., Vancheva, T., Lefeuvre, P., Jones, J. B., Timilsina, S., Minsavage, G. V., Vallad, G. E., and Koebnik, R. 2016. Whole-genome sequences of Xanthomonas euvesicatoria strains clarify taxonomy and reveal a stepwise erosion of type 3 effectors. Front. Plant Sci. 7:1-12.

Bessetti, J. 2007. An introduction to PCR inhibitors. Promega Corporation. Retrieved 11 Jan 2016 from http://www.promega.com/ /media/files/ resources/profiles $\% 20 \mathrm{in} \% 20 \mathrm{dna} / 1001 / \mathrm{an} \% 20 \mathrm{introduction} \% 20$ to $\% 20 \mathrm{pcr} \%$ 20inhibitors.pdf

Bonas, U., Schulte, R., Fenselau, S., Minsavage, G. V., Staskawicz, B. J., and Stall, R. E. 1991. Isolation of a gene cluster from Xanthomonas campestris pv. vesicatoria that determines pathogenicity and the hypersensitive response on pepper and tomato. Mol. Plant-Microbe Interact. 4:81-88.

Bouzar, H., Jones, J. B., Stall, R. E., Hodge, N. C., Minsavage, G. V., Benedict, A. A., and Alvarez, A. M. 1994. Physiological, chemical, serological, and pathogenic analyses of a worldwide collection of Xanthomonas campestris pv. vesicatoria strains. Phytopathology 84:663-671.

Cho, J. C., and Tiedje, J. M. 2001. Bacterial species determination from DNADNA hybridization by using genome fragments and DNA microarrays. Appl. Environ. Microbiol. 67:3677-3682.

Constantin, E. C., Cleenwerck, I., Maes, M., Baeyen, S., Van Malderghem, C., De Vos, P., and Cottyn, B. 2016. Genetic characterization of strains named as Xanthomonas axonopodis pv. dieffenbachiae leads to a taxonomic revision of the $X$. axonopodis species complex. Plant Pathol. 65: 792-806.

Cornelis, G. R. 2006. The type III secretion injectisome. Nat. Rev. Microbiol. 4:811-825.

Dhama, K., Karthik, K., Chakraborty, S., Tiwari, R., Kapoor, S., Kumar, A., and Thomas, P. 2014. Loop-mediated isothermal amplification of DNA (LAMP): A new diagnostic tool lights the world of diagnosis of animal and human pathogens: A review. Pak. J. Biol. Sci. 17:151-166.

Doidge, E. M. 1921. A tomato canker. Ann. Appl. Biol. 7:407-430.

Graham, J. H., Gottwald, T. R., and Fardelmann, D. 1990. Cultivar-specific interactions for strains of Xanthomonas campestris from Florida that cause citrus canker and citrus bacterial spot. Plant Dis. 74:753-756.

Horvath, D. M., Stall, R. E., Jones, J. B., Pauly, M. H., Vallad, G. E., Dahlbeck, D., Staskawicz, B. J., and Scott, J. W. 2012. Transgenic resistance confers effective field level control of bacterial spot disease in tomato. PLoS One 7: e42036.

Hoy, M. A., Jeyaprakash, A., and Nguyen, R. 2001. Long PCR is a sensitive method for detecting Liberibacter asiaticum in parasitoids undergoing risk assessment in quarantine. Biol. Control 22:278-287.

Jalan, N., Aritua, V., Kumar, D., Yu, F., Jones, J. B., Graham, J. H., Setubal, J. C., and Wang, N. 2011. Comparative genomic analysis of Xanthomonas axonopodis pv. citrumelo $\mathrm{F} 1$, which causes citrus bacterial spot disease, and related strains provides insights into virulence and host specificity. J. Bacteriol. 193:6342-6357.

Jones, J. B., Lacy, G. H., Bouzar, H., Stall, R. E., and Schaad, N. W. 2004. Reclassification of the xanthomonads associated with bacterial spot disease of tomato and pepper. Syst. Appl. Microbiol. 27:755-762.

Jones, J. B., Pohronezny, K. L., Stall, R. E., and Jones, J. P. 1986. Survival of Xanthomonas campestris pv. vesicatoria on tomato crop residue, weeds, seeds, and volunteer tomato plants. Phytopathology 76:430-434.

Kim, J., and Easley, C. J. 2011. Isothermal DNA amplification in bioanalysis: Strategies and applications. Bioanalysis 3:227-239.

Koenraadt, H., Van Betteray, B., Germain, R., Hiddink, G., Jones, J. B., and Oosterhof, J. 2009. Development of specific primers for the molecular detection of bacterial spot of pepper and tomato. Acta Hort. 808:99-102.

Kubota, R., Vine, B. G., Alvarez, A. M., and Jenkins, D. M. 2008. Detection of Ralstonia solanacearum by loop-mediated isothermal amplification. Phytopathology 98:1045-1051. 
Leite, R. P., Jr., Jones, J. B., Somodi, G. C., Minsavage, G. V., and Stall, R. E. 1995. Detection of Xanthomonas campestris pv. vesicatoria associated with pepper and tomato seed by DNA amplification. Plant Dis. 79:917-922.

Leite, R. P., Minsavage, G. V., Bonas, U., and Stall, R. E. 1994. Detection and identification of phytopathogenic Xanthomonas strains by amplification of DNA sequences related to the hrp genes of Xanthomonas campestris pv. vesicatoria. Appl. Environ. Microbiol. 60:1068-1077.

Louws, F. J., Wilson, M., Campbell, H. L., Cuppels, D. A., Jones, J. B., Shoemaker, P. B., Sahin, F., and Miller, S. A. 2001. Field control of bacterial spot and bacterial speck of tomato using a plant activator. Plant Dis. 85:481-488.

Mackay, I. M., Arden, K. E., and Nitsche, A. 2002. Real-time PCR in virology. Nucleic Acids Res. 30:1292-1305.

McGuire, R. G., Jones, J. B., and Sasser, M. 1986. Tween media for semiselective isolation of Xanthomonas campestris pv. vesicatoria from soil and plant material. Plant Dis. 70:887-891.

Momol, T., Jones, J., Olson, S., Obradovic, A., Balogh, B., and King, P. 2008. Integrated management of bacterial spot on tomato in Florida. University of Florida. Retrieved 28 Oct 2015 from http://ufdc.ufl.edu/IR00003017/00001

Noël, L., Thieme, F., Nennstiel, D., and Bonas, U. 2002. Two novel type IIIsecreted proteins of Xanthomonas campestris pv. vesicatoria are encoded within the hrp pathogenicity island. J. Bacteriol. 184:1340-1348.

Obradovic, A., Mavridis, A., Rudolph, K., Janse, J. D., Arsenijevic, M., Jones, J. B., Minsavage, G. V., and Wang, J. F. 2004. Characterization and PCRbased typing of Xanthomonas campestris pv. vesicatoria from peppers and tomatoes in Serbia. Eur. J. Plant Pathol. 110:285-292.

Palacio-Bielsa, A., Cubero, J., Cambra, M. A., Collados, R., Berruete, I. M., and López, M. M. 2011. Development of an efficient real-time quantitative PCR protocol for detection of Xanthomonas arboricola pv. pruni in Prunus species. Appl. Environ. Microbiol. 77:89-97.

Piepenburg, O., Williams, C. H., Stemple, D. L., and Armes, N. A. 2006. DNA detection using recombination proteins. PLoS Biol. 4:e204.

Pohronezny, K., Stall, R. E., Canteros, B. I., Kegley, M., Datnoff, L. E., and Subramanya, R. 1992. Sudden shift in the prevalent race of Xanthomonas campestris pv. vesicatoria in pepper fields in South Florida. Plant Dis. 76:118-120.

Pohronezny, K., and Volin, R. B. 1983. The effect of bacterial spot on yield and quality of fresh market tomatoes. HortScience 18:69-70.

Potnis, N., Timilsina, S., Strayer, A., Shantharaj, D., Barak, J. D., Paret, M. L., Vallad, G. E., and Jones, J. B. 2015. Bacterial spot of tomato and pepper: Diverse Xanthomonas species with a wide variety of virulence factors posing a worldwide challenge. Mol. Plant Pathol. 16:907-920.

Rademaker, J. L., Hoste, B., Louws, F. J., Kersters, K., Swings, J., Vauterin, L., Vauterin, P., and de Bruijn, F. J. 2000. Comparison of AFLP and rep-PCR genomic fingerprinting with DNA-DNA homology studies: Xanthomonas as a model system. Int. J. Syst. Evol. Microbiol. 50:665-677.

Ritchie, D. F. 2000. Bacterial spot of pepper and tomato. The Plant Health Instructor.

Rossier, O., Van den Ackerveken, G., and Bonas, U. 2000. HrpB2 and hrpF rom Xanthomonas are type III-secreted proteins and essential for pathogenicity and recognition by the host plant. Mol. Microbiol. 38:828-838.

Schochetman, G., Ou, C. Y., and Jones, W. K. 1988. Polymerase chain reaction. J. Infect. Dis. 158:1154-1157.
Scott, J. W., Somodi, G. C., and Jones, J. B. 1989. Resistance to bacterial spot fruit infection in tomato. HortScience 24:825-827.

Silva, G., Bömer, M., Nkere, C., Kumar, P. L., and Seal, S. E. 2015. Rapid and specific detection of Yam mosaic virus by reverse-transcription recombinase polymerase amplification. J. Virol. Methods 222:138-144.

Stack, J., Arif, M., Rascoe, J., Nakhla, M., and Busot, G. 2016. Recombinase polymerase-based diagnostics for in-field detection of Pseudomonas syringae pv. actinidiae. 2016 APS Annual Meeting. Retrieved 26 Apr 2018 from https://www. apsnet.org/meetings/Documents/2016_meeting_abstracts/aps2016_818.htm

Stall, R. E., Jones, J. B., and Minsavage, G. V. 2009. Durability of resistance in tomato and pepper to xanthomonads causing bacterial spot. Annu. Rev. Phytopathol. 47:265-284.

Strayer, A. L., Jeyaprakash, A., Minsavage, G. V., Timilsina, S., Vallad, G. E., Jones, J. B., and Paret, M. L. 2016. A multiplex real-time PCR assay differentiates four xanthomonas species associated with bacterial spot of tomato. Plant Dis. 100:1660-1668.

Temple, T. N., and Johnson, K. B. 2011. Evaluation of loop-mediated isothermal amplification for rapid detection of Erwinia amylovora on pear and apple fruit flowers. Plant Dis. 95:423-430.

Timilsina, S., Jibrin, M. O., Potnis, N., Minsavage, G. V., Kebede, M., Schwartz, A., Bart, R., Boyer, C., Vallad, G. E., Pruvost, O., Jones, J. B., and Goss, E. M. 2015. Multilocus sequence analysis of xanthomonads causing bacterial spot of tomato and pepper plants reveals strains generated by recombination among species and recent global spread of Xanthomonas gardneri. Appl. Environ. Microbiol. 81:1520-1529.

Trébaol, G., Manceau, C., Tirilly, Y., and Boury, S. 2001. Assessment of the genetic diversity among strains of Xanthomonas cynarae by randomly amplified polymorphic DNA analysis and development of specific characterized amplified regions for the rapid identification of $X$. cynarae. Appl. Environ. Microbiol. 67:3379-3384.

TwistDx. 2017. Appendix to the TwistAmp ${ }^{\mathrm{TM}}$ reaction kit manuals. Retrieved 20 Sep 2017 from https://www.twistdx.co.uk/docs/default-source/RPAassay-design/newappendix(2).pdf?sfvrsn=8

Vallad, G., Pernezny, K., and Momol, T. 2004. A Series on Disease in the Florida Vegetable Garden: Tomato. University of Florida IFAS Extension, Gainesville, FL.

Vauterin, L., Hoste, B., Kersters, K., and Swings, J. 1995. Reclassification of Xanthomonas. Int. J. Syst. Bacteriol. 45:472-489.

Yang, W., Sacks, E. J., Lewis Ivey, M. L., Miller, S. A., and Francis, D. M. 2005. Resistance in Lycopersicon esculentum intraspecific crosses to race T1 strains of Xanthomonas campestris pv. vesicatoria causing bacterial spot of tomato. Phytopathology 95:519-527.

Yasuhara-Bell, J., Kubota, R., Jenkins, D. M., and Alvarez, A. M. 2013. Loopmediated amplification of the Clavibacter michiganensis subsp. michiganensis micA gene is highly specific. Phytopathology 103:1220-1226.

Young, J. M., Park, D. C., Shearman, H. M., and Fargier, E. 2008. A multilocus sequence analysis of the genus Xanthomonas. Syst. Appl. Microbiol. 31:366-377.

Zanoli, L. M., and Spoto, G. 2012. Isothermal amplification methods for the detection of nucleic acids in microfluidic devices. Biosensors (Basel) 3: $18-43$. 